\title{
Factors determining the fluctuation of fluoride concentrations in PM10 aerosols in the urbanized coastal area of the Baltic Sea (Gdynia, Poland)
}

\author{
Anita Lewandowska • Lucyna Falkowska • \\ Joanna Jóźwik
}

Received: 12 October 2012 / Accepted: 21 February 2013 / Published online: 28 March 2013

(C) The Author(s) 2013. This article is published with open access at Springerlink.com

\begin{abstract}
Fluoride concentrations were determined in PM10 samples collected in the urbanized coastal area of the Baltic Sea (Gdynia) in the period between 1 August 2008 and 8 January 2010. $\mathrm{F}^{-}$concentrations remained within the range of 0.4 $36.6 \mathrm{ng} \cdot \mathrm{m}^{-3}$. The economic transformations which have taken place in Poland increasing ecological awareness have had an excellent effect on the levels of fluoride pollution in the air of the studied region. In our measurements, fluoride concentrations increased in wintertime, when air temperature dropped, at low wind speeds $\left(<1 \mathrm{~m} \cdot \mathrm{s}^{-1}\right)$ and with low dispersion of pollutants originating from local sources (traffic, industry, domestic heating). At times when wind speed grew to $>10 \mathrm{~m} \cdot \mathrm{s}^{-1}$, fluorides were related to marine aerosols or else brought from distant sources. Apart from wind speed and air temperature, other significant meteorological parameters which determined the variability of $\mathrm{F}^{-}$turned out to be air humidity and precipitation volume. Aerosols were washed out effectively, even with small precipitation ( $h=4 \mathrm{~mm}$ ), and if a dry period lasted for several days, their concentrations grew rapidly to over $30.0 \mathrm{ng} \cdot \mathrm{m}^{-3}$.
\end{abstract}

Keywords PM10 · Fluoride - Synoptic conditions ·

Air mass influence $\cdot$ Coastal zone

\section{Introduction}

Fluorine occurs in the environment in the air, in the soil and in living organisms. Fluorides are released into the environment

Responsible editor: Gerhard Lammel

A. Lewandowska $(\bowtie) \cdot$ L. Falkowska $\cdot$ J. Jóźwik

Institute of Oceanography, University of Gdańsk, Al. Marszałka J.

Piłsudskiego 46, 81-378 Gdynia, Poland

e-mail: a.lewandowska@ug.edu.pl naturally through the weathering and dissolution of minerals, in emissions from volcanoes and in marine aerosols. Fluorides are also released into the environment via coal combustion and from various industrial processes, including steel manufacture, primary aluminium, copper and nickel production, phosphate ore processing, phosphate fertilizer production and use, glass, brick and ceramic manufacturing, and glue and adhesive production. The use of fluoride-containing pesticides, as well as the controlled fluoridation of drinking-water supplies, also contributes to the release of fluoride from anthropogenic sources (WHO 2002).

Airborne fluoride exists in gaseous and particulate forms emitted from both natural and anthropogenic sources. The gaseous fluorides include hydrogen fluoride, carbon tetrafluoride $\left(\mathrm{CF}_{4}\right)$, hexafluoroethane $\left(\mathrm{C}_{2} \mathrm{~F}_{6}\right)$ and silicon tetrafluoride. Particulate fluorides include cryolite, chiolite $\left(\mathrm{Na}_{5} \mathrm{Al}_{3} \mathrm{~F}_{14}\right)$, calcium fluoride, aluminium fluoride and sodium fluoride. Fluoride released as gaseous and particulate matter is deposited in the general vicinity of an emission source (Low and Bloom 1988). Natural sources of atmospheric fluorides are volcanic eruptions and geysers, and it is estimated that emissions from those sources amount to between $60 \mathrm{Gg}$ and $6 \mathrm{Tg} \mathrm{F}^{-}$-year ${ }^{-1}$ (Franzaring et al. 2007). Another $20 \mathrm{Gg} \mathrm{F}^{-} \cdot$ year $^{-1}$ is introduced into the atmosphere through marine aerosols.

The fate of inorganic fluorides in the atmosphere is primarily influenced by vaporization, aerosol formation, wet and dry deposition and hydrolysis (Viswanathan et al. 2009). Fluorides adsorbed on particulate matter in the atmosphere are generally stable and are not readily hydrolyzed, although they may be degraded by radiation if they persist in the atmosphere. Fluoride in aerosols can be transported over large distances by wind or as a result of atmospheric turbulence. The distance travelled is determined by the deposition velocity of both the gaseous hydrogen fluoride and the fluorides in particulate form. The long-range transport 
effectiveness depends on the particle size and is easier for the finest fraction of aerosols (Sloof et al. 1989).

Fluorine participates in the metabolism of plants, animals and humans (Machoy et al. 1995). In small concentrations, it is a necessary element, while high concentrations are toxic for mammals. The harmless daily dose of fluorine for an adult human is about $1 \mathrm{mg}$, but as little as about $5 \mathrm{mg}$ may lead to chronic fluorine poisoning, known as fluorosis, as this element accumulates in the system - mainly in the teeth and bones (Whitford 1990).

In the Tri-city agglomeration (Gdansk-Sopot-Gdynia metropolitan area), studies on fluorides in aerosols were carried out in the 1990s. They returned high values exceeding the daily fluoride limit of $3 \mu \mathrm{g} \cdot \mathrm{m}^{-3}$, established in 1990 by the ordinance of the Minister of Environmental Protection, by up to $900 \%$ (Jaśkowski et al. 2001). The most controversial source of fluorides in the region was then a stack of phosphogypsum, a by-product of sulphuric acid production, belonging to the Gdansk Phosphoric Fertilizers Producer. Located on Sobieszewo Island, to the south-west of the test station, it was closed down by the end of 2009 by order of the Gdansk city authorities. In view of the health of the inhabitants of Gdansk and its vicinity, it seems important to determine the concentration of fluorides in PM10 aerosols again, now that the highest potential source of these ions has been eliminated.

The main purpose of the research described herein was to plug gaps in the knowledge concerning the seasonal concentration variation of fluoride in PM10 in the urbanized coastal zone, where fluoride can be both of natural and anthropogenic origin. The intention, therefore, was to assess the relationship between fluoride concentration in PM10 and synoptic condition (wind speed, air temperature, relative humidity, wet deposition amount) as well as to identify the various sources of fluorides in the region, including the role of the sea.

\section{Materials and methods}

\section{Sampling}

PM10 samples for fluoride determination were taken between 1 August 2008 and 8 January 2010 in 48-h cycles. Measurements were performed in Gdynia, around 1,000 m from the Baltic Sea coast, on the roof of the Institute of Oceanography building ( $\left.\varphi=54^{\circ} 51^{\prime} \mathrm{N}, \lambda=18^{\circ} 54^{\prime} \mathrm{E}\right)$ (Fig. 1). The height of the building ( 20 ma.s.l.) enables measurements to be taken from above the levels of neighbouring tree canopies and buildings. Gdynia is a city with a population of around 250 thousand people, located close to agricultural and industrial centres (e.g. shipyards, food processing and chemical plants, including phosphogypsum, and port facilities). Two other large cities - Gdansk and Sopot — are in close proximity to Gdynia. Altogether, the population of the so-called Tri-city agglomeration is nearly one million.

PM10 samples were collected by means of a Low Volume Sampler (LVS-3) with PM10 inlet produced by ATMOSERVICE (Poland) and INGENIEURBÜRO NORBERT DERENDA (Germany). The inlet corresponds with the European standard CEN EN 12341, as well as VDI 2463 paragraph 7 and 8, TA-LUFT and VDI-2465 paragraph 1 and 2 standards, and is treated as a reference inlet. The air flow was maintained at a level of $2.3 \mathrm{~m}^{3} \cdot \mathrm{h}^{-1}$. Temperature and humidity in the sampler were controlled by means of a heating and ventilation system.

All 210 samples were collected on Whatman Q-MA filters, $47 \mathrm{~mm}$ in diameter and with a nominal pore size of $2.2 \mu \mathrm{m}$, which were heated at a temperature of $550{ }^{\circ} \mathrm{C}$ for a minimum of $6 \mathrm{~h}$ using a furnace, in order to eliminate volatile impurities and reduce blank values. This kind of filter is commonly used all over the world and is recommended by the World Meteorological Organization for the collection of PM10 samples. The detection limit for PM10 was $0.17 \mu \mathrm{g} \cdot \mathrm{m}^{-3}$ for 30 replicates. The reproducibility uncertainty of the PM10 method was $4.1 \%$ (at a certainty level of $99 \%$ ).

After sampling, concentrations of PM10 (in $\mu \mathrm{g} \cdot \mathrm{m}^{-3}$ ) were obtained by dividing the difference of filter weights (before and after sampling) by the sampled air volume. All procedures connected with weight measurements were performed with an accuracy of $10^{-5} \mathrm{~g}$ using the XA balance (RADWAG) at a temperature of $23 \pm 2{ }^{\circ} \mathrm{C}$ and a relative humidity of $40 \pm 5 \%$.

\section{Chemical analysis of fluoride in PM 10}

The analysis of fluoride ions in PM10 samples was conducted using the ion chromatography method on the 850 Professional IC chromatograph by Metrohm, in accordance with the Polish Norm PrPN-EN No 10304-1 (PN 1995). A Metrosep A Supp 7-250 anion column (6.1006.630) was used. In the case of the studied ions, the detection limit amounted to $0.2 \mathrm{ng} \cdot \mathrm{m}^{-3}$, and the reproducibility uncertainty, at a certainty level of $99 \%$, taking into account 42 blank samples, was at a level of $2.7 \%$.

Prior to commencing the analysis, round pieces of $1 \mathrm{~cm}$ in diameter were cut out of the filters, submerged in $12 \mathrm{~cm}^{3}$ of deionised milli-Q water and placed in a ultrasonic bath for $30 \mathrm{~min}$ in order to extract the components from the filter into a solution. Next, the samples were analyzed using an ion chromatograph. In the present study, a $3.6 \mathrm{mM}$ sodium carbonate solution was used as an eluent. The flow of the solution through the column was $0.9 \mathrm{~cm}^{-3} \cdot \mathrm{min}^{-1}$.

Statistical methods of data analysis and result compilation

In the event of tests of significance, the Szapiro-Wilk test was used in order to check data parameterization, the Mann-Whitney 
Fig. 1 Map of the Tri-city with Gdynia sampling station (IO UG) and location of major sources of fluorides in the region

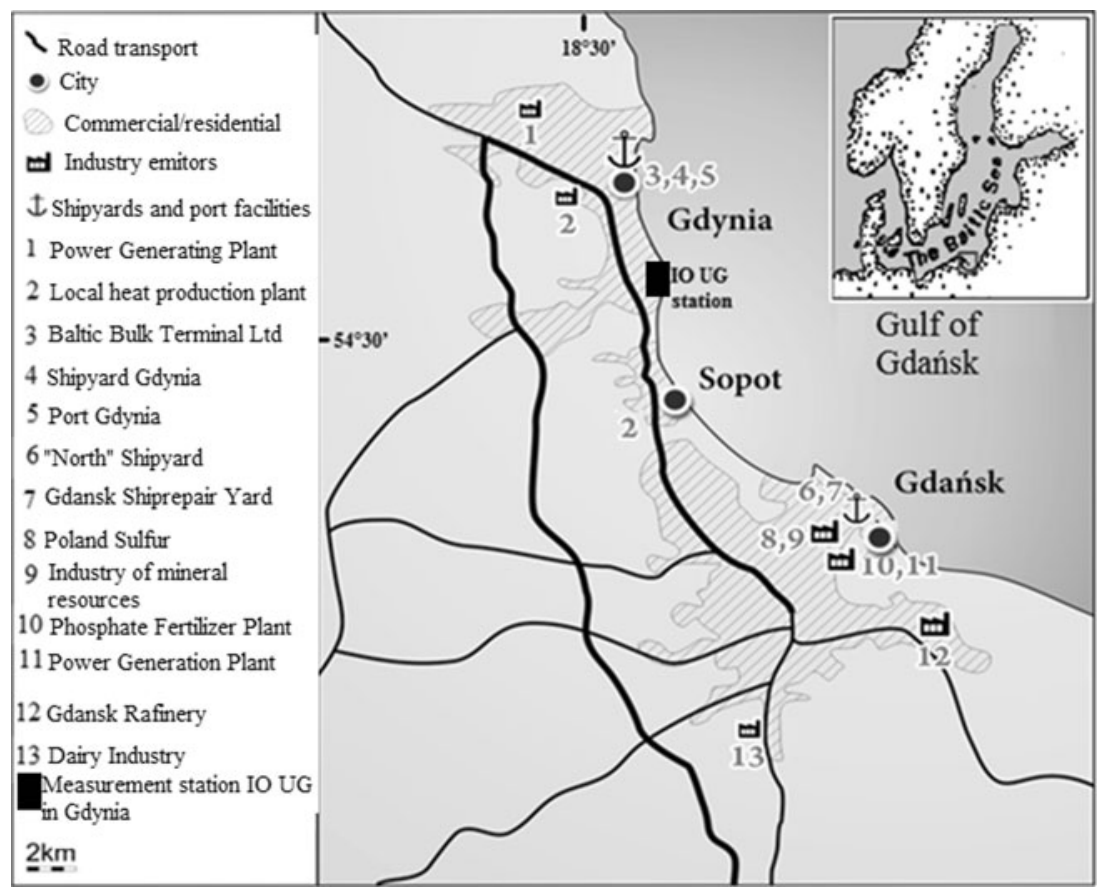

$U$ test was used to compare two autonomous tests, and the ANOVA test was used to compare several autonomous tests.

\section{Meteorological conditions}

During the measurement period, meteorological data (i.e. wind direction and speed, air temperature and humidity and precipitation volume) were measured by the Huger Weather Station on the roof of the Institute of Oceanography building. The data are available at http://153.19.140.100/wx200_data/. Because wind speed measurements were conducted, as with all other measurements, at a height of $20 \mathrm{~m}$ above sea level, the value was corrected for $\mathrm{u}_{10}$ using the formula given by Schwarzenbach et al. (1993) (Lewandowska et al. 2010).

Using the HYSPLIT model (Draxler and Rolph 2003; Rolph 2003; www.arl.noaa.gov/ready.html), 48-h air mass backward trajectories at 3-h intervals were calculated. Starting heights of 500,1,000 and 1,500 m were used, depending on boundary layer height at the sampling site for a given period. HYSPLIT is a complete system for computing simple air parcel trajectories to complex dispersion and deposition simulations. These backward trajectories take into consideration the share of maritime and continental influence, and the pollution level of the surpassed areas (Table 1). The classification scheme, which was described carefully in a previous paper (Lewandowska et al. 2010), consisted of three aerosol types. Aerosols carried to Gdynia from the north and northwest were always influenced by the maritime environment (type 1), while aerosols from other directions were influenced by continental environments (types 2 and 3 ). The second type of air mass from the eastern sector describes clean or partially polluted aerosols, mainly of terrigenic origin, and the third type denotes rather polluted aerosols influenced by continental areas which were carried out to the Gdynia coastal station from the south and south-west (Lewandowska et al. 2010).

\section{Results and discussion}

Mass concentration of PM10 aerosols amounted to $24.2 \mu \mathrm{g} \cdot \mathrm{m}^{-3}$ on average, with the median at a level of $18.6 \mu \mathrm{g} \cdot \mathrm{m}^{-3}$ (Fig. 2a). The maximum value was observed in the period between 21 and 23 December $2009\left(79.3 \mu \mathrm{g} \cdot \mathrm{m}^{-3}\right)$ and the minimum between 12 and 14 September $2008\left(5.4 \mu \mathrm{g} \cdot \mathrm{m}^{-3}\right)$ (Fig. 2b). The PM10

Table 1 Aerosol classification according to the backward trajectories (Lewandowska et al. 2010)

\begin{tabular}{cccc}
\hline Classification & Pollution state & $\begin{array}{c}\text { Source } \\
\text { region }\end{array}$ & $\begin{array}{l}\text { Regions crossed by back } \\
\text { trajectories }\end{array}$ \\
\hline $\begin{array}{c}\text { Maritime- } \\
\text { continental }\end{array}$ & $\begin{array}{c}\text { Clean and } \\
\text { moderately } \\
\text { polluted }\end{array}$ & 1 & $\begin{array}{c}\text { Atlantic. North Sea. } \\
\text { Baltic Sea. Arctic } \\
\text { Ocean. North Europe. } \\
\end{array}$ \\
& & $\begin{array}{l}\text { Scandinavia. Finland. } \\
\text { Denmark. British } \\
\text { islands. }\end{array}$ \\
Continental & Clean and & 2 & $\begin{array}{c}\text { Polar regions. North and } \\
\text { eastern Russia Baltic }\end{array}$ \\
& moderately & & States. Belarus \\
& polluted & & Western and central \\
& Polluted & 3 & Europe. South Russia. \\
& & & Ukraine. South Poland \\
& & &
\end{tabular}



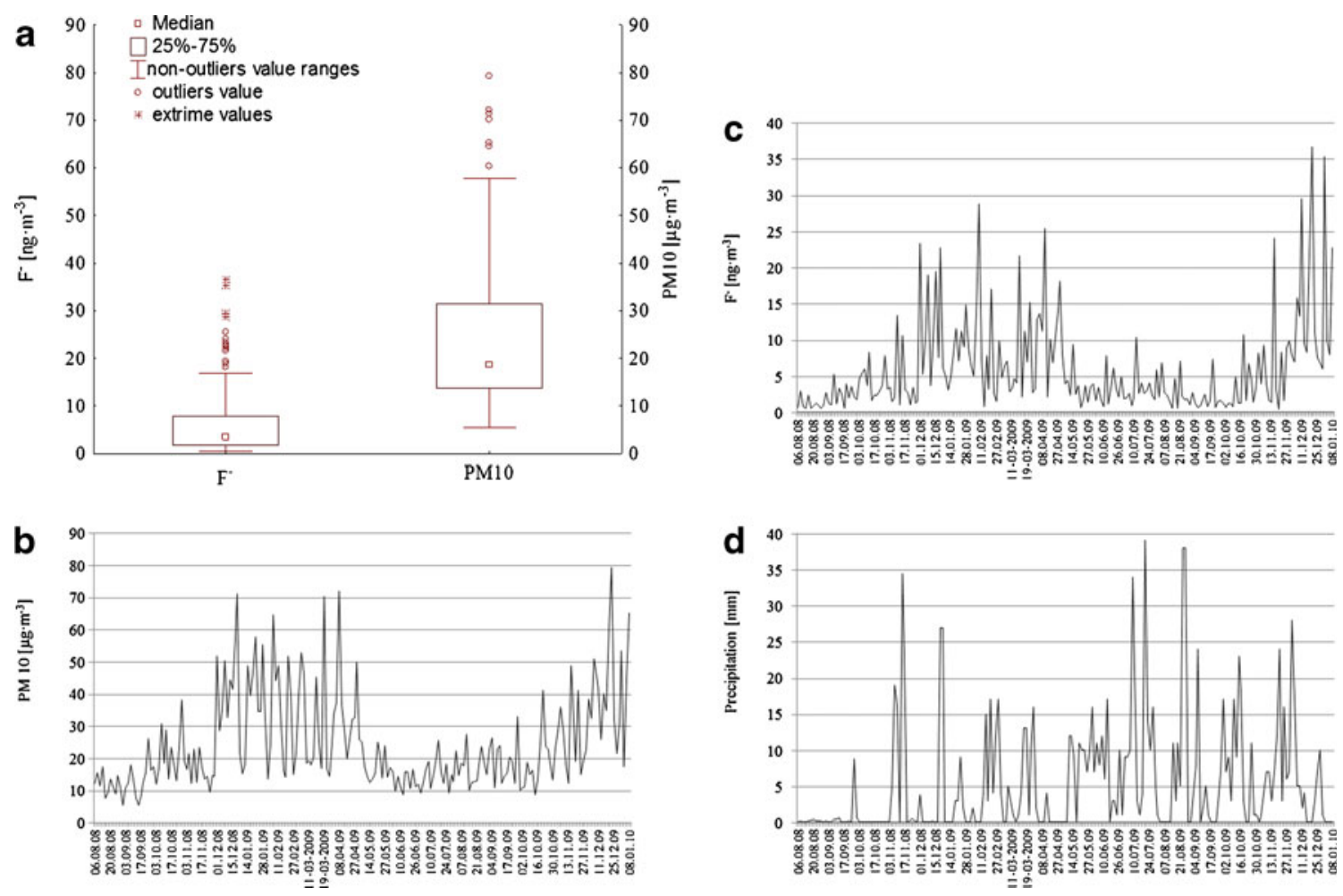

Fig. 2 The range of fluoride $\left(\mathrm{ng} \cdot \mathrm{m}^{-3}\right)$ and PM10 $\left(\mu \mathrm{g} \cdot \mathrm{m}^{-3}\right)$ concentration (a), fluctuations of fluoride concentration in PM10 $\left(\mathrm{ng} \cdot \mathrm{m}^{-3}\right)(\mathbf{b}), \mathrm{PM} 10$ concentration $\left(\mu \mathrm{g} \cdot \mathrm{m}^{-3}\right)(\mathbf{c})$ and precipitation $(\mathrm{mm})(\mathbf{d})$ over Gdynia between 1 August 2008 and 8 January 2010

concentrations measured at the IO UG station in Gdynia were within the range typical of other large European cities in Austria, Germany, Switzerland or Holland (from 24 to $38 \mu \mathrm{g} \cdot \mathrm{m}^{-3}$ ) (Querol et al. 2004). In Gdynia, PM10 aerosol concentrations in excess of the permitted value set for a $24-\mathrm{h}$ period $\left(50 \mu \mathrm{g} \mathrm{m}^{-3}\right)$ occurred at different wind speeds and from different directions of advection. However, such events always happened during the cold period. It was determined that there were three types of episodes of high concentration of PM10 aerosols: local, regional and long-distance origin. A detailed characterization of the changeability of PM10 concentrations in the atmosphere over Gdynia during the discussed study and a description of high-concentration episodes of aerosols smaller than $10 \mu \mathrm{m}$ in diameter has been presented by Lewandowska and Falkowska (2013).

Fluoride concentration in the period between 1 August 2008 and 8 January 2010 varied within the range of 0.4 to $36.6 \mathrm{ng}$. $\mathrm{m}^{-3}$ (Fig. 2c). The mean $\mathrm{F}^{-}$concentration value in aerosols amounted to $6.0 \mathrm{ng} \cdot \mathrm{m}^{-3}$ over Gdynia, with the median at a level of $3.5 \mathrm{ng} \cdot \mathrm{m}^{-3}$ (Fig. 2a). Fluoride concentration in Gdynia was very low compared to other regions of the world, especially when precipitation occurred (Fig. 2d). For example, in Holland, in an area devoid of fluorine sources, the concentration of this element approached $30 \mathrm{ng} \cdot \mathrm{m}^{-3}$ and increased to $70.0 \mathrm{ng} \cdot \mathrm{m}^{-3}$ in urbanized areas (IPCS 1984). Levels of airborne fluoride usually do not exceed $3.0 \mathrm{\mu g} \mathrm{m}^{-3}$ and are higher in urban than in rural locations (WHO 2002). In areas which are not in the direct vicinity of emission sources, the mean concentrations of fluoride in ambient air are much lower. For example, in arctic regions of Canada, fluoride concentration ranges between 2 and $7 \mathrm{ng} \cdot \mathrm{m}^{-3}$ (Barrie and Hoff 1985). All fluoride concentration values mentioned above are representative of the 1980s and 1990s. Air concentrations are expected to be different today in view of changes in industries and the wider use of pollution control devices. However, data on the concentration of fluoride in PM10 for Europe appear to be unique. For this reason, it is not certain whether these changes will definitely lead to a reduction in the concentration of fluoride in the air.

Natural concentration level of fluorides in PM10 in the atmosphere over Gdynia

Any value up to $0.5 \mathrm{ng} \cdot \mathrm{m}^{-3}$ (IPCS 1984) is considered to be a natural level of fluoride concentration in the air. During the study period, there were 12 events of concentrations below the natural fluoride value in the atmosphere, constituting $6 \%$ of all data. Minimum values for the concentration of ions in PM10 were obtained in the period between 18 and 20 November 2009 at southern advection (type 3 of air masses) (Fig. 3a). At that time, the wind speed in Gdynia was at the highest velocity recorded during the entire study period, 
Fig. 3 Characteristic of wind speed $\left(\mathrm{m} \cdot \mathrm{s}^{-1}\right)$ and air mass direction type (a) and relative humidity (\%) and ambient temperature $\left({ }^{\circ} \mathrm{C}\right)(\mathbf{b})$ over Gdynia between 1 August 2008 and 8 January 2010
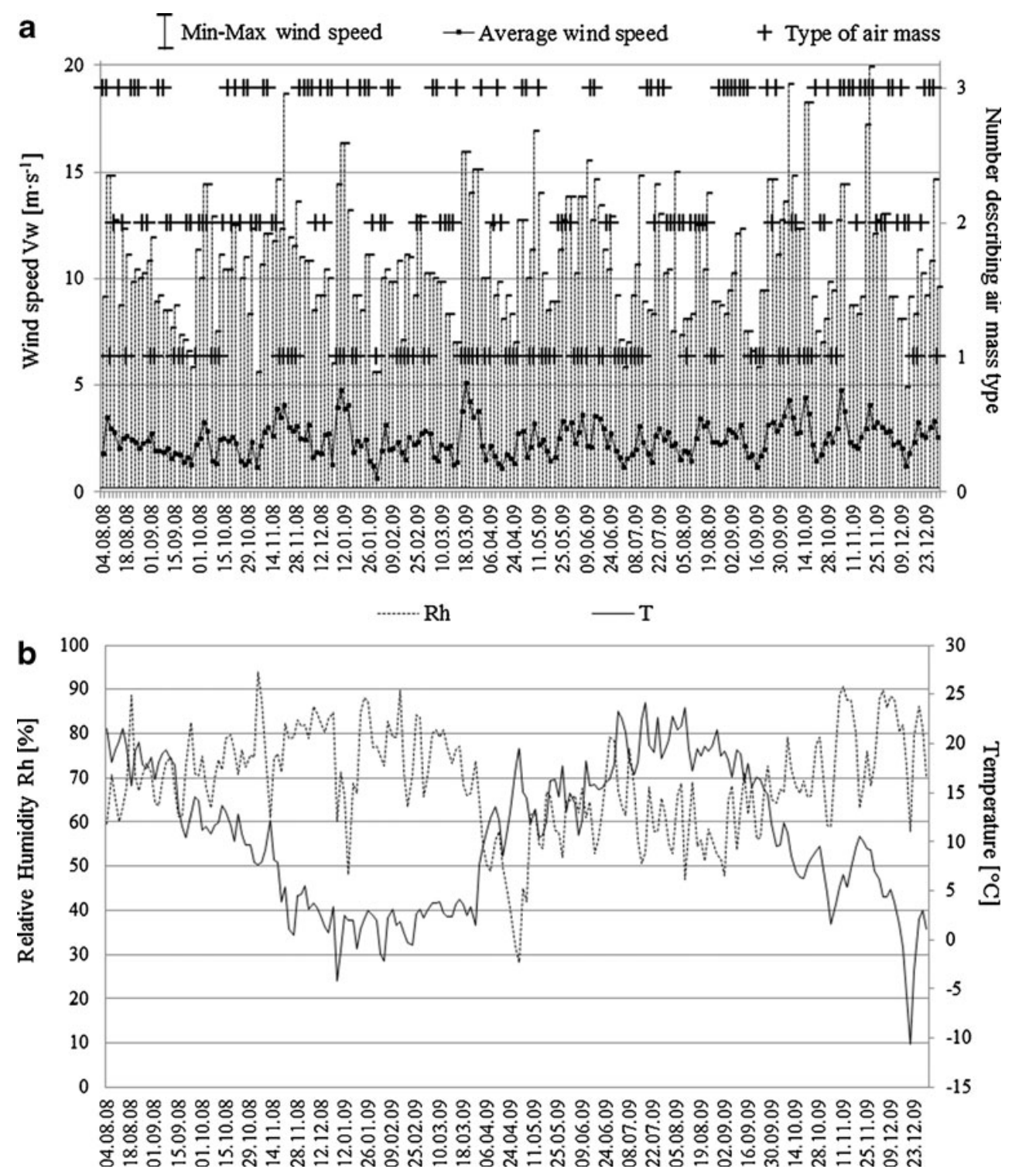

reaching $19.7 \mathrm{~m} \cdot \mathrm{s}^{-1}$, and a very strong dispersion of local pollutants took place. Atmospheric fluorides can be transported over long distances as a result of wind or atmospheric turbulence (WHO 2002). Air temperature at that time was unusual for November, reaching $17{ }^{\circ} \mathrm{C}\left(10.5{ }^{\circ} \mathrm{C}\right.$ on average) (Fig. 3b), and humidity was also low, averaging $63 \%$ and periodically as little as $34 \%$. Such meteorological conditions were not conducive to the conversion of gaseous fluoride fractions (HF) into particles (Neumüller 1981; Weast 1986). Apart from in November 2009, very low fluoride concentrations, around the background level, were also observed in August and at the beginning of September, in both 2008 and 2009. None of the advection types was observed to be predominant, but there was always an increase in wind speed over $10 \mathrm{~m} \cdot \mathrm{s}^{-1}$ and a drop in air humidity to the median value of $34.7 \%$. Mean air temperature was also high $\left(16.0^{\circ} \mathrm{C}\right)$. Background fluoride concentration values have shown that air pollution decreases at the end of the summer, when there is good ventilation and dry warm air masses are brought over the coastal zone of the Gulf of Gdansk. This has been confirmed additionally by the fact that, at that time, PM10 concentrations were at their lowest levels (Fig. 2b).

Low values of fluoride concentrations were also observed when the volume of precipitation increased (Fig. 2c, d). Such a situation took place in July 2009 when a rainfall of several days (from 29.06 to 08.07), amounting to a total of $38.7 \mathrm{~mm}$, caused the fluoride concentration values to drop by an order of magnitude (from 7.8 to $0.8 \mathrm{ng} \cdot \mathrm{m}^{-3}$ ).

Local sources of fluoride in PM10 in the atmosphere over Gdynia

Seasonal changeability was noted with regard to fluoride concentrations in aerosols over Gdynia (Fig. 4). During the 


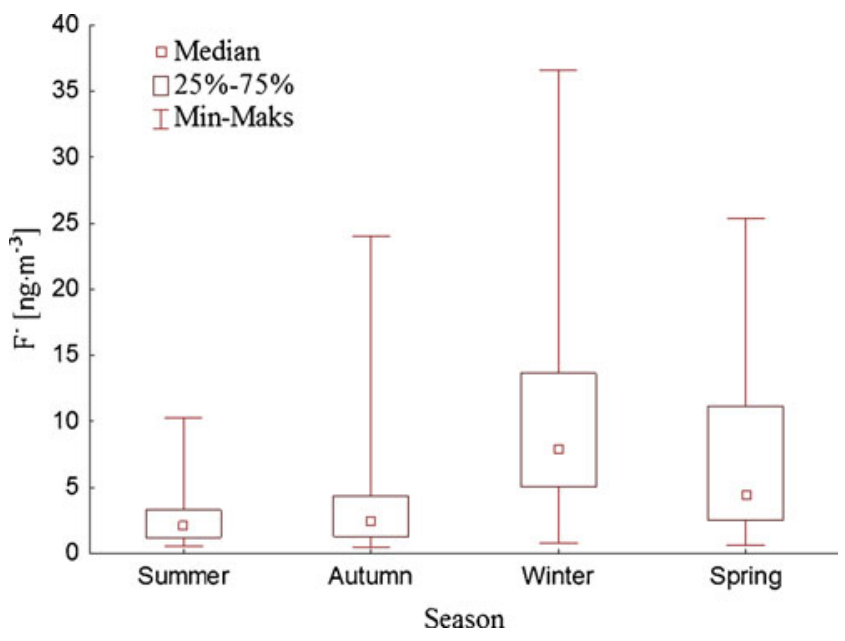

Fig. 4 The range of fluoride concentrations $\left(\mathrm{ng} \cdot \mathrm{m}^{-3}\right)$ in PM10 aerosols over Gdynia during particular seasons (between 1 August 2008 and 8 January 2010)

warm months (from May to September), the concentration of fluoride ions was low, averaging $3.5 \mathrm{ng} \cdot \mathrm{m}^{-3}$ with the maximum equal to $10.3 \mathrm{ng} \cdot \mathrm{m}^{-3}$ (Fig. 2c). However, the median value increased nearly threefold between late autumn and early spring, amounting to $10.2 \mathrm{ng} \cdot \mathrm{m}^{-3}$ on average (Fig. 4). The most significant increase in the concentration of fluorides occurred during the cold period when fossil fuel combustion was at its highest level. Winter episodes of high fluoride concentrations in PM10 aerosols were related to lasting high atmospheric pressure and persistent thermal inversion, which limited the vertical mixing of air. They were accompanied by south winds blowing at low speeds, averaging $2.1 \mathrm{~m} \cdot \mathrm{s}^{-1}$ for all episodes (Figs. 3a and 5 ). At such times, fluoride concentrations showed their highest values $\left(10.9-28.8 \mathrm{ng} \cdot \mathrm{m}^{-3}\right)$ and were related to pollutants brought over from local sources (Figs. 1 and 3a). In the study area, a significant amount of PM10 originated from low-level sources related to domestic heating located to the south of the measurement station. Its share during the heating period may have amounted to as much as $50 \%$ of all emission (WIOŚ 2009). Coal constitutes as much as $80 \%$ of all fuel used in the communal-utility sector for heat production, and fluorine is one of the by-products of coal combustion which are emitted into the atmosphere (Buńczyk and Daniluk 2003). Industrial point sources (from technological and power industries) are also responsible for aerosol emission. However, in the 1990s, a structural change occurred, and the impact of industry was exceeded by that of low-level emission (WIOŚ 2009).

When air masses were brought from the west, fluoride concentration in aerosols was similar to that observed at southern advection (10.7-29.4 $\left.\mathrm{ng} \cdot \mathrm{m}^{-3}\right)$ and was the result of increased traffic in the streets of the city and in the nearby thoroughfares (Figs. 1, 3a and 5). In the region, transportation is responsible for $30 \%$ of PM10 emission into the atmosphere (WIOŚ 2009). Fluorine is one of the components of teflon, a material that is chemically inert and resistant to high temperatures, which is used in the motoring industry to produce seals. Additionally, hydrogen fluoride is used as a catalyst in the synthesis of high-octane petrol. Both compounds are emitted into the atmosphere as products of incomplete combustion when traffic intensifies. Moreover, when western advection was predominant and wind speeds were low, very high concentrations of elemental carbon (EC) in PM10 were observed in Gdynia (Lewandowska and Falkowska 2013). In a polluted atmosphere, elemental carbon comes mostly from diesel engine emissions. It does not undergo further transformations and is a direct indicator of traffic intensification, particularly in larger cities (Ruellan and Cachier 2001; Ryall et al. 2002). In Gdynia, between 26 and 28 December 2009, the share of EC was at its highest level during the entire measurement period $(15.8 \%)$. At the same time, there was an increase in fluoride concentration up to $24.8 \mathrm{ng} \cdot \mathrm{m}^{-3}$. Detailed analysis has proven a directly proportional increase in fluoride and elemental carbon concentrations in aerosols when wind speed was no higher than $1 \mathrm{~m} \cdot \mathrm{s}^{-1}$, suggesting that in the studied cases, both compounds originated from a local, traffic-related source (Table 2) (Fig. 1).

At northern advection, fluorides in PM10 had on average lower concentrations than with the other directions (median $12.8 \mathrm{ng} \cdot \mathrm{m}^{-3}$ ) and were brought from over the area of the harbour, the transshipment base and from heating plants (Figs. 1, 3a, 4 and 5). However, in the period between 18
Fig. 5 Fluoride concentration $\left(\mathrm{ng} \cdot \mathrm{m}^{-3}\right)$ in aerosols over Gdynia between 1 August 2008 and 8 January 2010 , at various advection types

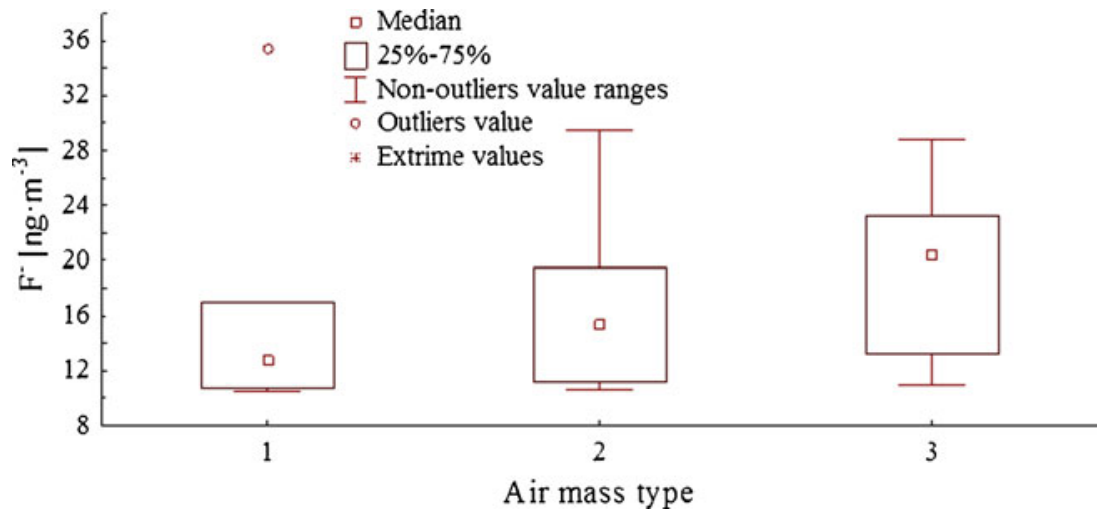


Table 2 The values of the correlation coefficient $(r)$ and the regression equation for fluoride and elemental carbon concentrations in PM10 aerosols (results come from Lewandowska et al. 2010) in the function of wind speed

\begin{tabular}{lll}
\hline $\begin{array}{l}\text { Wind speed } \\
\left(\mathrm{m} \cdot \mathrm{s}^{-1}\right)\end{array}$ & $\begin{array}{l}\text { Correlation coefficient } \\
\left(r^{2}, p<0.05\right)\end{array}$ & $\begin{array}{l}\text { Regression } \\
\text { equation }\end{array}$ \\
\hline$<3$ & 0.26 & $y=2.15+0.06 \cdot x$ \\
$<1.5$ & 0.23 & $y=2.30+0.06 \cdot x$ \\
$<1.0$ & 0.99 & $y=0.63+0.52 \cdot x$ \\
\hline
\end{tabular}

and 20 December 2009, when there was no atmospheric precipitation over four consecutive days, the highest fluoride concentration $\left(36.6 \mathrm{ng} \cdot \mathrm{m}^{-3}\right)$ in PM10 aerosols in the whole of the study period was determined (Fig. 2c, d). Another interesting instance of an increase in fluoride concentration in aerosols up to the value of $35.4 \mathrm{ng} \cdot \mathrm{m}^{-3}$ was observed at northern advection around New Year's Day (between 30 December 2009 and 1 January 2010). At that time, fluorine compounds were emitted into the atmosphere probably from fireworks set off in large numbers. Pyrotechnical mixtures are rich in both calcium fluoride, commonly known as fluorite $\left(\mathrm{CaF}_{2}\right)$, and in cryolite $\left(\mathrm{Na}_{3} \mathrm{AlF}_{6}\right)$ (http://pyrocreations.com). That night, the wind velocity had not exceeded $1.0 \mathrm{~m} \cdot \mathrm{s}^{-1}$, and the distribution of pollutants was very poor. Additionally, since 28 December, there had been no atmospheric precipitation (Figs. 2d and 3a).

Biomass combustion influence on fluoride in PM10 in the atmosphere over Gdynia

Biomass combustion is an anthropogenic factor which triggered a several-fold increase in fluoride concentration in relation to the mean value characteristic of the heating period. This phenomenon was observed in early spring, when air masses were brought from the north-east and east (Fig. 6a). In the study period, from 13 to 15 April 2009, when wind speed reached $9.6 \mathrm{~m} \cdot \mathrm{s}^{-1}, \mathrm{~F}^{-}$concentrations in PM10 amounted to $25.4 \mathrm{ng} \cdot \mathrm{m}^{-3}$ (Figs. $2 \mathrm{c}$ and 3a). At that time, air masses were brought over from north-eastern Poland, the Kaliningrad Oblast and partly from over Lithuania, where in the week preceding 15 April, some very intense fires had taken place (Fig. 6b). At that time, PM10 concentrations increased to $72 \mu \mathrm{g} \cdot \mathrm{m}^{-3}$ (Fig. 2b). Very high $\mathrm{F}^{-}$ion concentrations were characteristic of the whole of April 2009 in general. At that time, fires to the east and north-west of Poland persisted most of the time until 20 May 2009 (http://rapidfire.sci.gsfc.nasa.gov/firemaps). In addition, it was a very poor month in terms of rainfall (Fig. 2d). Only the period between 15 and 17 April 2009 was an exception, when precipitation amounting to $4 \mathrm{~mm}$ effectively contributed to the reduction of fluoride concentration in aerosols by an order of magnitude $\left(2.1 \mathrm{ng} \cdot \mathrm{m}^{-3}\right)$ in relation to the April average $\left(12.0 \mathrm{ng} \cdot \mathrm{m}^{-3}\right)$. Additional high concentrations of fluoride in PM10 (14.0 and $18.1 \mathrm{ng} \cdot \mathrm{m}^{-3}$, respectively) over Gdynia as a result of biomass burning were observed twice (24-26 April and 26-28 April 2009) (Fig. 2c). At those times, the wind speed was high $\left(12.5 \mathrm{~m} \cdot \mathrm{s}^{-1}\right)$, air masses were brought over from north-east, and there was no precipitation on the route of the air masses (Figs. 2d and 3a).

Marine origin fluoride in PM10 in the atmosphere over Gdynia

At the coastal station located in Gdynia, a relationship between northern advection and the transportation of fluorides in marine aerosols was noted (Table 3). When sea spray components react with sulphuric and/or nitric acid to form sodium sulphate and/or nitrate together with $\mathrm{HCl}$ and $\mathrm{HF}$, the degasification from marine aerosol occurs. However, hydrofluoric acid is approximately five orders of magnitude less soluble than hydrochloric acid and will therefore be degassed from marine aerosols more readily than hydrochloric acid. Hydrofluoric acid is expected to be depleted in aged marine aerosols, and this may be a significant source of hydrogen fluoride in the troposphere (Brimblecombe and Clegg 1988). When, over the test station, wind speed increased periodically to over $10 \mathrm{~m} \cdot \mathrm{s}^{-1}$, the lifting of spume was intensified, along with the breaking of sea waves and dispersion of water vapour, in which circumstances, sea spray aerosols are effectively generated (Nair et al. 2006; Pérez et al. 2008). Fluorides, which occur in sea water in concentrations of $1.2-1.5 \mathrm{mg} \cdot \mathrm{dm}^{-3}$ (Datta et al. 2000), were therefore introduced into the atmosphere together with sea salt. The relationship was confirmed by a statistically significant correlation coefficient between sodium chloride concentrations and fluorides for selected cases $(r=0.98, n=6$, $p<0.05$ ). Mahadevan et al. (1986) reported a strong correlation between fluoride and sodium concentrations in precipitation samples collected from marine, coastal and inland sites in India. The authors suggested that fluoride in precipitation was derived from the cycling of sea salt. Over Gdynia, in the discussed instances of marine advection predominance, the average $\mathrm{F}^{-}$concentration was $13.9 \mathrm{ng} \cdot \mathrm{m}^{-3}$ and increased to $17.2 \mathrm{ng} \cdot \mathrm{m}^{-3}(18-19 \mathrm{March}$ 2009) when the proportion of sodium chloride in PM10 was the highest (57.2\%), and wind speed reached up to $13.5 \mathrm{~m} \cdot \mathrm{s}^{-1}$ (Lewandowska and Falkowska 2013). Given that air humidity was low at that time $(66 \%)$ and air masses had not encountered precipitation on their way, marine aerosols could have been brought over the measurement station (Table 3). As with other advection types, in the case of marine advection, there was a drop in fluoride concentration when rainfall occurred (15-16 October 2009). 
Fig. 6 Air mass trajectories (a) in periods of high biomass burning (8-15 April 2009) in north-eastern and eastern Europe (b) (http:// rapidfire.sci.gsfc.nasa.gov/ firemaps) a

NOAA HYSPLIT MODEL

Backward trajectories ending at 0900 UTC 15 Apr 09

GDAS Meteorological Data

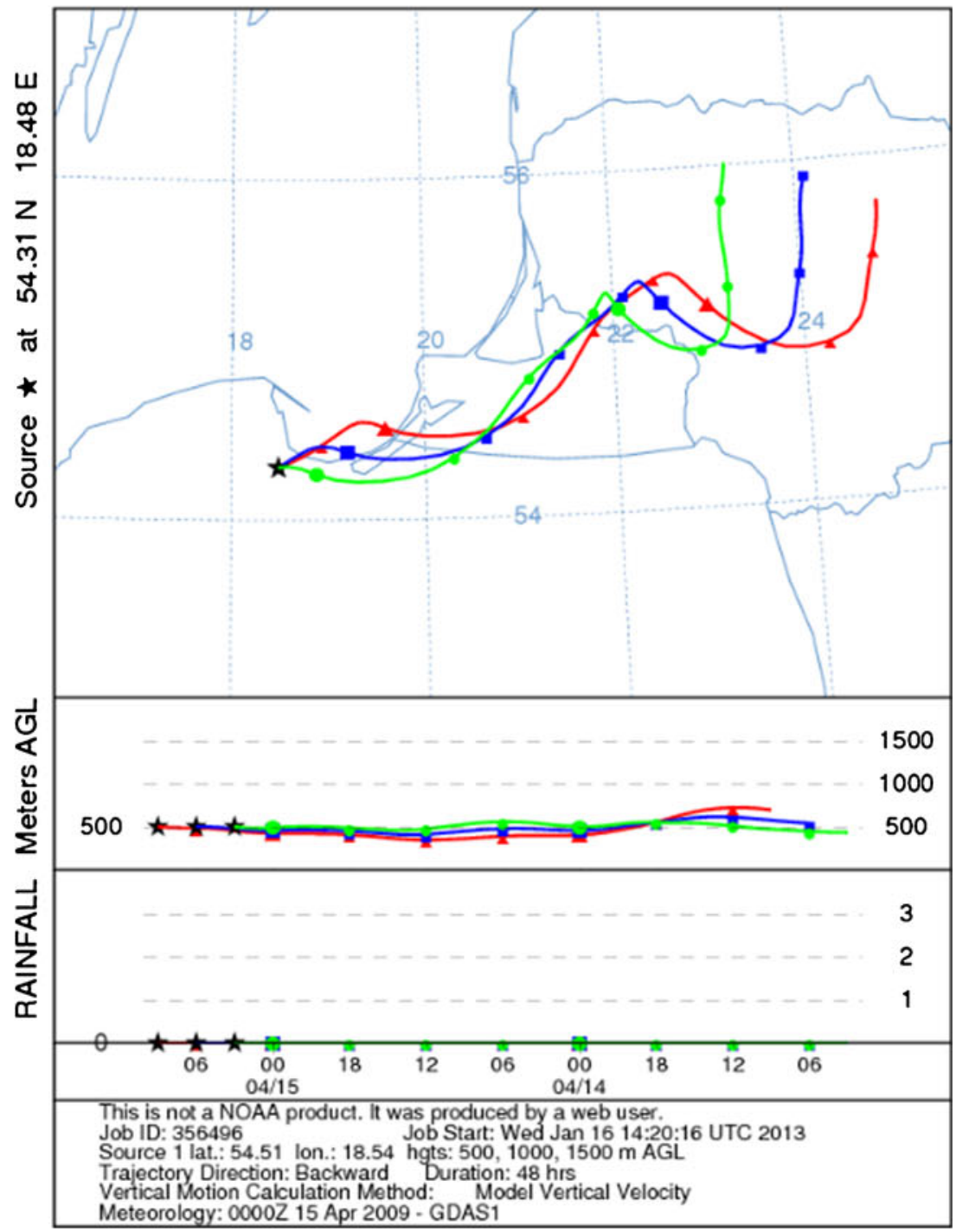

b

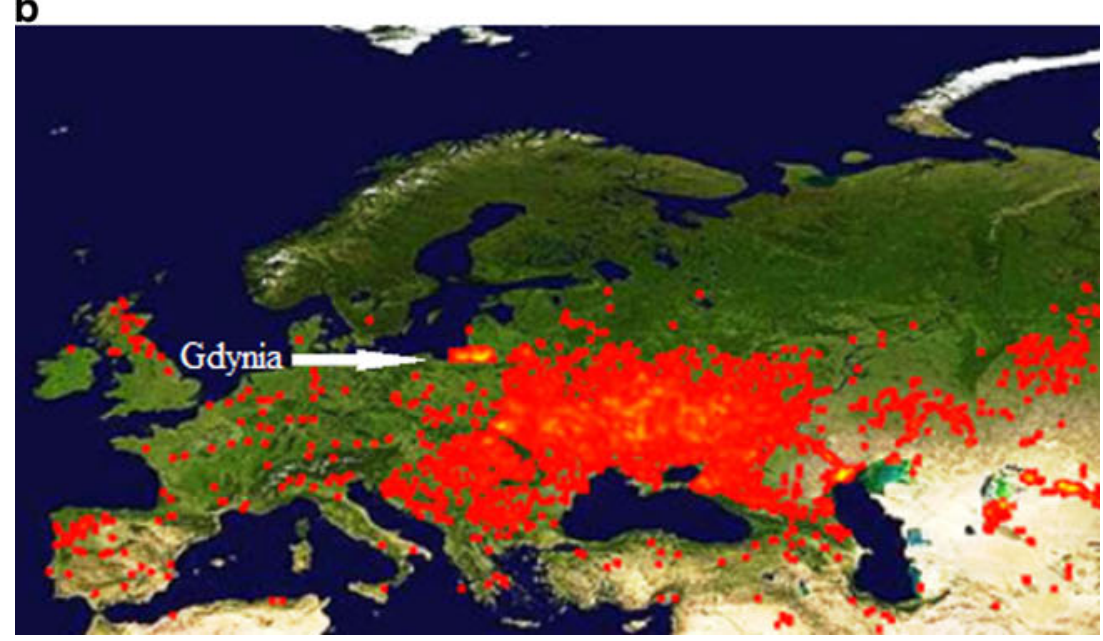


Table 3 The characteristics of high fluoride concentrations in marine aerosols over Gdynia in 2009

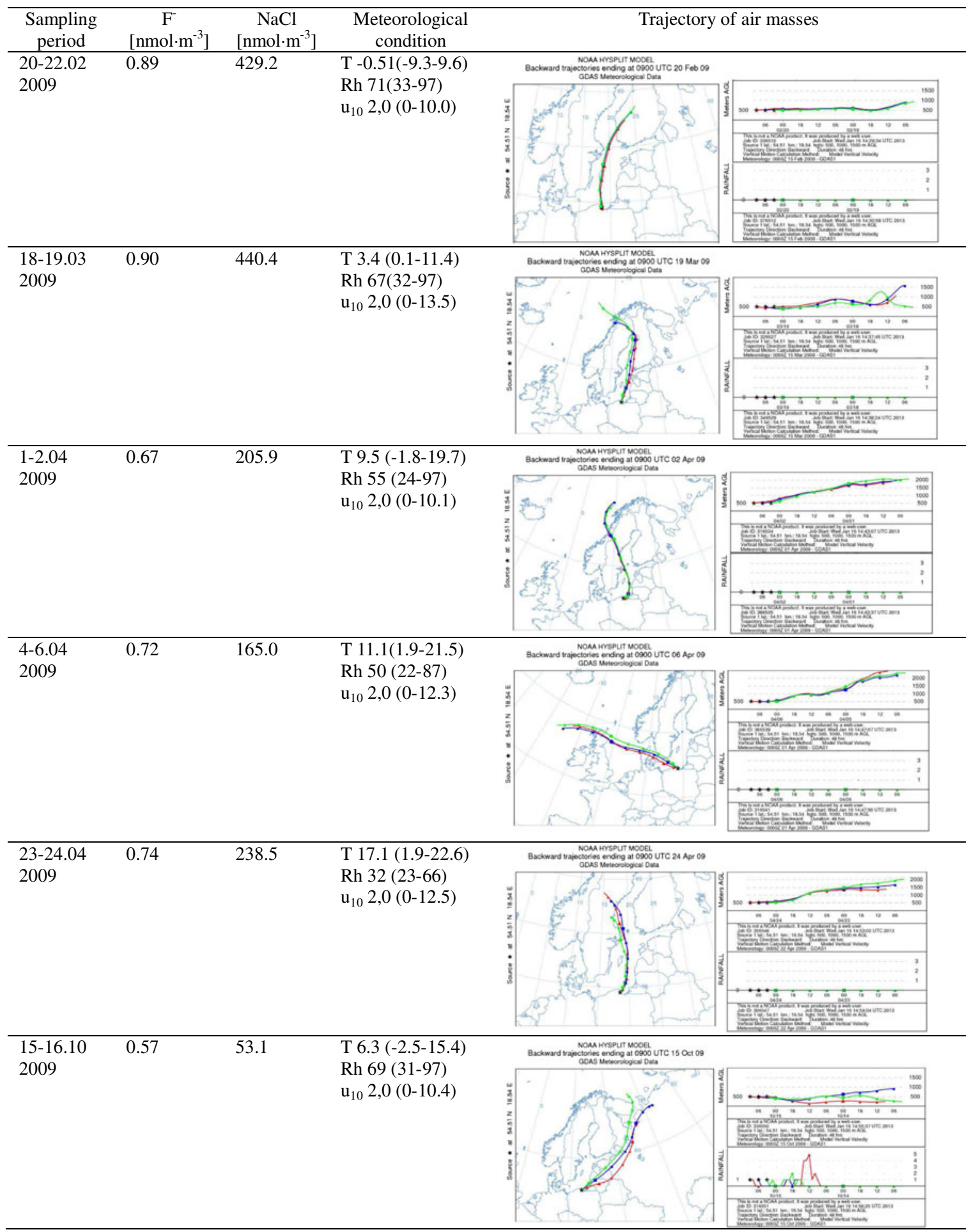

Symbols: T-air temperature $\left[{ }^{\circ} \mathrm{C}\right], \mathrm{Rh}$ - air humidity [\%], u10- wind speed [m·s-1] correction calculated using the formula given by Schwarzenbach et al. (1993); Data of $\mathrm{NaCl}$ is presented in Lewandowska and Falkowska (2013)

\section{Conclusions}

Fluoride concentrations in aerosols ranged between 0.4 and $36.6 \mathrm{ng} \cdot \mathrm{m}^{-3}$, values which testify to the low importance of this element to air pollution in the coastal zone of the Gulf of Gdansk when compared with other regions of the world. When dry and warm air masses were brought over the study area from southern Europe, 
fluorides occurred in PM10 aerosols in natural background concentrations. Compared to earlier results, the present ones do not indicate a health threat to the inhabitants of the region.

The wide range of fluoride concentrations in aerosols (two orders of magnitude) testifies to significant changeability in the influence of origin sources. The influence of anthropopressure was the most pronounced in the heating season, when combustion processes were intensified in the communal-utility sector. Transportation and traffic were also linked to higher fluoride concentrations. It was found that in all cases, local sources were predominant at low wind speeds and low pollutant dispersion in the region. When wind speed increased to over $10 \mathrm{~m} \cdot \mathrm{s}^{-1}$, distant sources started playing a significant role in the formation of fluoride concentrations in PM10 over Gdynia. Those sources were related to fires and biomass combustion as well as to marine aerosol emission.

Meteorological factors determining fluoride concentration in PM10 aerosols, beside temperature and wind velocity, turned out to be air humidity and precipitation volume. Fluorides were effectively washed out together with aerosols even by a little precipitation $(h=4 \mathrm{~mm})$, and their concentration grew rapidly whenever a dry period persisted for some time.

Open Access This article is distributed under the terms of the Creative Commons Attribution License which permits any use, distribution, and reproduction in any medium, provided the original author(s) and the source are credited.

\section{References}

Barrie LA, Hoff RM (1985) Five years of air chemistry observations in the Canadian arctic. Atmos Environ 19(12):1995-2010

Buńczyk A, Daniluk A (2003) Thermal power in Poland-preliminary results. Bulletin of the Energy Regulatory Office 6:33

Brimblecombe P, Clegg SL (1988) The solubility and behavior of acid gases in the marine aerosol. J Atmos Chem 7:1-18

Datta DK, Gupta LP, Subramanian V (2000) Dissolved fluoride in the lower Ganges-Brahmaputra-Meghna River system in the Bengal Basin, Bangladesh. Environ Geol 39:1163-1168

Draxler RR, Rolph GD (2003) HYSPLIT (HYbrid Single-Particle Lagrangian Integrated Trajectory) Model access via NOAA ARL READY Website (http://www.arl.noaa.gov/ready/ hysplit4.html). NOAA Air Resources Laboratory, Silver Spring, MD

Franzaring J, Klumpp A, Fangmeier A (2007) Active biomonitoring of airborne fluoride near an HF producing factory using standardised grass cultures. Atmos Environ 41:4828-4840

IPCS (1984) Fluorine and fluorides. Geneva, World Health Organization, International Programme on Chemical Safety (Environmental Health Criteria 36)

Jaśkowski J, Leśnikowska K, Terlecki J, Prokop A (2001) Fluoride. Fluorosis in the Pomeranian province. Fluor. Fluoroza w województwie pomorskim. http://simpgda.webpark.pl/pliki/ (in polish).fluor.doc

Lewandowska A, Falkowska L (2013) High concentration episodes of PM10 in the air over the urbanized coastal zone of the Baltic Sea (Gdynia-Poland). Atmos Res 120-121:55-67

Lewandowska A, Falkowska L, Murawiec D, Pryputniewicz D, Burska D, Bełdowska M (2010) Elemental and organic carbon in aerosols over urbanized coastal region (southern Baltic Sea, Gdynia). Sci Tot Environ 408(20):4761-4769

Low PS, Bloom H (1988) Atmospheric deposition of fluoride in the lower Tamar Valley, Tasmania. Atmos Environ 22(9):20492056

Machoy Z, Dąbrowska ED, Samujło D, Ogoński T, Raczyński J, Gabczyńska Z (1995) Relationship between fluoride content In bones and age In European elk (Alces alces L.). Comp Biochem Physiol 111C:117-120

Mahadevan TN, Meenakshy V, Mishra UC (1986) Fluoride cycling in nature through precipitation. Atmos Environ 20:1745-1749

Nair PR, George SK, Sunilkumar SV, Parameswaran K, Salu J, Annamma A (2006) Chemical composition of aerosols over peninsular India during winter. Atmos Environ 40:6477-6493

Neumüller O (1981) Römpps Chemie Lexikon, 8th ed. Vol. 2. Stuttgart, Franck'sch Verlagshandlung

Pérez N, Pey J, Querol X, Alastuey A, López JM, Viana M (2008) Partitioning of major and trace components in PM10-PM2,5-PM1 at an urban site in southern Europe. Atmos Environ 42:1677-1691

PN (Polish Norme) (1995) Determination of dissolved fluoride, chloride, nitrite, orthophosphate, bromide, nitrate and sulphate using ion chromatography. Polish Committee for Standardization, the standard number BS EN ISO 10304-1

Querol X, Alastuey A, Ruiz CR, Artiñano B, Hansson HC, Harrison RM, Buringh E, ten Brink HM, Lutz M, Bruckmann P, Straehl P, Schneider J (2004) Speciation and origin of PM10 and PM2.5 in selected European cities. Atmos Environ 38:6547-6555

Rolph GD (2003) Real-time Environmental Applications and Display system (READY) Website (http://www.arl.noaa.gov/ready/ hysplit4.html). NOAA Air Resources Laboratory, Silver Spring, MD

Ruellan S, Cachier H (2001) Characterization of fresh particulate vehicular exhaust near a Paris high flow road. Atmos Environ 35:453-468

Ryall DB, Derwent RG, Manning AJ, Redington AL, Cirden J, Milington W, Semmonds PG, Doherty S, Carslaw N, Fuller GW (2002) The origin of high particulate concentration over the United Kingdom, March 2000. Atmos Environ 36:1363-1378

Schwarzenbach RP, Gschwend PM, Imboden DM (1993) Environmental organic chemistry. John Wiley \&Sons, New York

Sloof W, Eerens H, Janus J, Ros J (1989) Integrated criteria document: Fluorides. Bilthoven, National Institute of Public Health and Environmental Protection (Report No. 758474010)

Viswanathan G, Jaswanth A, Gopalakrishnan S, Sivailango S (2009) Mapping of fluoride endemic areas and assessment of fluoride exposure. Sci Tot Environ 407:1578-1587

Weast R (1986) CRC handbook of chemistry and physics, 1985-1986. CRC Press, Boca Raton, Florida

Whitford GM (1990) The physiological and toxicological characteristics of fluoride. J Dent Res 69:539-549

WIOŚ (2009) Annual assessment of air quality in the Pomeranian province in 2008, Pomeranian Voivodship Inspector for Environmental Protection in Gdańsk 45 pp. (in Polish)

WHO (2002) Environmental Health Criteria 227. Fluorides. WHO, Geneva, pp 20-61 